\title{
REVIEWS
}

\section{Measures of Organizational Culture and Climate in Primary Care: a Systematic Review}

\author{
Kimberly S. Hsiung, MD, $\mathrm{MS}^{1,2}{ }^{\mathbb{D}}$, Jason B. Colditz, MEd ${ }^{7}$, Elizabeth A. McGuier, $P \mathrm{hD}^{7}$, \\ Galen E. Switzer, $P h D^{3,4}$, Helena M. VonVille, MLS, MPH ${ }^{5}$, Barbara L. Folb, MM, MLS, MPH ${ }^{5}$, \\ and David J. Kolko, $P h D^{7,6}$
}

'University of Pittsburgh School of Medicine, Pittsburgh, PA, USA; ${ }^{2}$ Clinical and Translational Science Institute, University of Pittsburgh, Pittsburgh, PA, USA; ${ }^{3}$ Department of Medicine, University of Pittsburgh, Pittsburgh, PA, USA; ${ }^{4}$ Center for Health Equity Research and Promotion (CHERP), Veterans Affairs Pittsburgh Healthcare System, Pittsburgh, PA, USA; ${ }^{5}$ Health Sciences Library System, University of Pittsburgh, Pittsburgh, PA, USA; ${ }^{6}$ UPMC Western Psychiatric Hospital, Pittsburgh, PA, USA.

BACKGROUND: Primary care is increasingly contributing to improving the quality of patient care. This has imposed significant demands on clinicians with rising needs and limited resources. Organizational culture and climate have been found to be crucial in improving workforce well-being and hence quality of care. The objectives of this study are to identify organizational culture and climate measures used in primary care from 2008 to 2019 and evaluate their psychometric properties.

METHODS: Data sources include PubMed, PsycINFO, HAPI, CINAHL, and Mental Measurements Yearbook. Bibliographies of relevant articles were reviewed and a cited reference search in Scopus was performed. Eligibility criteria include primary health care professionals, primary care settings, and use of measures representing the general concept of organizational culture and climate. Consensus-Based Standards for the selection of health Measurement Instruments (COSMIN) guidelines were followed to evaluate individual studies for methodological quality, rate results of measurement properties, qualitatively pool studies by measure, and grade evidence.

RESULTS: Of 1745 initial studies, 42 studies met key study inclusion criteria, with 27 measures available for review ( 16 for organizational culture, 11 for organizational climate). There was considerable variability in measures, both conceptually and in psychometric quality. Many reported limited or no psychometric information.

DISCUSSION: Notable measures selected for frequent use and strength and applicability of measurement properties include the Culture Questionnaire adapted for health care settings, Practice Culture Assessment, and Medical Group Practice Culture Assessment for organizational culture. Notable climate measures include the Nurse Practitioner Primary Care Organizational Climate Questionnaire, Practice Climate Survey, and Task and Relational Climate Scale. This synthesis and appraisal of organizational culture and climate measures can help investigators make informed decisions in choosing a

Supplementary Information The online version of this article (https:// doi.org/10.1007/s11606-020-06262-7) contains supplementary material, which is available to authorized users.

Received May 20, 2020

Accepted September 21, 2020

Published online November 2, 2020 measure or deciding to develop a new one. In terms of limitations, ratings should be considered conservative due to adaptations of the COSMIN protocol for clinician populations.

PROSPERO REGISTRATION NUMBER: CRD 42019133117

KEY WORDS: organizational culture; organizational climate; primary care; COSMIN.

J Gen Intern Med 36(2):487-99

DOI: $10.1007 / \mathrm{s} 11606-020-06262-7$

C Society of General Internal Medicine 2020

\section{INTRODUCTION}

In a nation with health care system flaws and rising costs, health care reformers and political leaders are looking to primary care for solutions. ${ }^{1}$ Primary care providers are charged with improving preventative care, managing chronic diseases, and keeping patients out of hospitals, but face significant challenges, including time pressure, documentation burden, and an increasingly aging population. ${ }^{2-4}$ Organizational factors, including organizational culture and climate, are increasingly recognized as crucial to strengthening the primary care workforce and improving the quality of primary care..$^{5-7}$

Organizational culture in health care is defined as the norms, values, and basic assumptions of a given organization, which drive both the quality of work life and the quality of care. ${ }^{8-10}$ Organizational climate is defined as the collective perception of the organization's culture and how it impacts personal well-being and functioning. ${ }^{10}$ Organizational culture and climate are interconnected; an organization's beliefs and values (culture) govern its members' experience (climate). Together, they make up the "feel" of an organization. ${ }^{11,12}$ Unfavorable organizational cultures, such as those characterized by chaotic work environments, time pressures, and lack of control, have been associated with poorer outcomes, including greater provider burnout. ${ }^{2,13}$ Hierarchical cultures and those resistant to change have also been identified as significant barriers to innovation and implementation of evidence- 
based practices. ${ }^{14-16}$ In contrast, favorable cultures and climates, such as those that enhance autonomy, promote diversity and inclusion, and facilitate cooperation and collaboration, are associated with better outcomes, including provider wellbeing and engagement in quality improvement. ${ }^{17,18}$

Moving forward with research on organizational culture and climate in primary care requires greater attention to measurement. Although many tools to measure culture and climate have been used in health care settings, variation in measure domains and psychometric properties makes it difficult to draw consistent and reliable conclusions. ${ }^{10,19,20}$ Additionally, measures developed for other types of health care organizations, such as hospitals, may not be valid for primary care. ${ }^{21}$ Identification of validated measures for primary care will encourage more informed instrument selection in future research and foster greater understanding of the organizational culture and climate of these settings, leading to effective and sustainable ways to achieve organizational changes that improve the quality of care.

We conducted a systematic review to identify measures of organizational culture and climate used in primary care within recent years (2008-2019) and evaluate their psychometric properties. We focused on measures used with primary care practitioners who have direct patient contact, whose experience of culture and climate is likely to have the most direct influence on patient outcomes. We aimed to formulate recommendations on instrument selection based on these findings and suggest directions for future research.

\section{METHODS}

\section{Protocol and Registration}

This systematic review follows the publishing guidelines set forth by PRISMA (Preferred Reporting Items for Systematic Reviews and Meta-Analyses), ${ }^{22}$ was assessed for quality using the AMSTAR checklist (https://amstar.ca/Amstar_Checklist. php), and contains a registered protocol with PROSPERO (CRD 42019133117). Our protocol is based on the Consensus-Based Standards for the selection of health Measurement Instruments (COSMIN) methodology. ${ }^{23-25}$

\section{Eligibility Criteria}

Eligibility criteria were determined a priori (Table 1). In summary, included articles met the following criteria: published 2008 and after, quantitative or mixed methodology were used, majority of the population were primary health care professionals, setting in primary care, and the target population completed an instrument measuring the general concept of organizational culture or organizational climate. Non-English articles were included; Google Translate was used to translate articles into English. ${ }^{26}$ Empirical research articles from journals and dissertations were included; cross-sectional, casecontrol, cohort studies, and clinical trials were also included.
Table 1 Study Eligibility Criteria

\begin{tabular}{|c|c|c|}
\hline $\begin{array}{l}\text { Study } \\
\text { component }\end{array}$ & Inclusion criteria & Exclusion criteria \\
\hline $\begin{array}{l}\text { Publication } \\
\text { type }\end{array}$ & $\begin{array}{l}\text { - Empirical research articles } \\
\text { from journals and dissertations; } \\
\text { cross-sectional, case-control, } \\
\text { cohort studies, clinical trials } \\
\text { - Studies using quantitative or } \\
\text { mixed methods }\end{array}$ & $\begin{array}{l}\text { - Articles outside } \\
\text { of original } \\
\text { research, including } \\
\text { reviews, opinions, } \\
\text { comments, } \\
\text { editorials, } \\
\text { conference } \\
\text { proceedings, } \\
\text { protocols, reports, } \\
\text { etc. } \\
\text { - Studies using } \\
\text { qualitative } \\
\text { methods only }\end{array}$ \\
\hline Population & $\begin{array}{l}\text { - }>50 \% \text { participants are primary } \\
\text { care health professionals who } \\
\text { have regular direct patient } \\
\text { contact, including physicians, } \\
\text { physician assistants, nurse } \\
\text { practitioners, nurses } \\
-\leq 50 \% \text { participants are primary } \\
\text { care health professionals, but a } \\
\text { representative subgroup analysis } \\
\text { has been performed on primary } \\
\text { care health professionals }\end{array}$ & $\begin{array}{l}\text { - Personnel who } \\
\text { do not have } \\
\text { regular direct } \\
\text { patient contact, } \\
\text { including staff, } \\
\text { administrators, } \\
\text { managers, } \\
\text { researchers, etc. }\end{array}$ \\
\hline $\begin{array}{l}\text { Intervention/ } \\
\text { exposure }\end{array}$ & $\begin{array}{l}\text { - Primary care settings } \\
\text { - Medical centers, Veterans } \\
\text { Affairs, hospitals, and health } \\
\text { care systems ONLY if they are } \\
\text { mentioned in the context of } \\
\text { primary care }\end{array}$ & $\begin{array}{l}\text { - Nonprimary care } \\
\text { settings } \\
\text { - Medical centers, } \\
\text { Veterans Affairs, } \\
\text { hospitals, and } \\
\text { health care } \\
\text { systems with no } \\
\text { mention of the } \\
\text { primary care } \\
\text { context }\end{array}$ \\
\hline Comparator & N/A & $\mathrm{N} / \mathrm{A}$ \\
\hline Outcome & $\begin{array}{l}\text { - Use of measures representing } \\
\text { the general concept of } \\
\text { organizational culture or } \\
\text { organizational climate } \\
\text { - Organizational culture and } \\
\text { climate are defined by the } \\
\text { following: } \\
\text { - "Organizational culture has } \\
\text { been defined as the norms, } \\
\text { values, and basic assumptions of } \\
\text { a given } \\
\text { organization....Organizational } \\
\text { climate, in comparison, more } \\
\text { closely reflects the employees' } \\
\text { perception of the organization's } \\
\text { culture; for example, it is a } \\
\text { collective reflection of their } \\
\text { experience of the culture.". }\end{array}$ & $\begin{array}{l}\text { - Measures } \\
\text { representing } \\
\text { specific concepts } \\
\text { of organizational } \\
\text { culture, including } \\
\text { research culture, } \\
\text { safety culture, } \\
\text { innovation culture, } \\
\text { etc. } \\
\text { - Measures } \\
\text { representing } \\
\text { specific concepts } \\
\text { of organizational } \\
\text { climate, including } \\
\text { team climate, } \\
\text { safety climate, } \\
\text { implementation } \\
\text { climate, etc. }\end{array}$ \\
\hline Time & $\begin{array}{l}\text { - Studies published on or after } \\
\text { 2008, up to the date the search is } \\
\text { performed }\end{array}$ & $\begin{array}{l}\text { - Studies } \\
\text { published before } \\
2008\end{array}$ \\
\hline
\end{tabular}

\section{Information Sources and Search Strategy}

Two health sciences librarians with systematic review experience (BF, HVV) developed searches for the databases PubMed, PsycINFO, HAPI (Health and Psychosocial Instruments), CINAHL (Current Index to Nursing and Allied Health Literature), and Mental Measurements Yearbook. The initial PubMed search was developed (BF) using a combination of MeSH terms; title, abstract, and keywords were checked against a known set of studies. The search was then adapted to search other databases (HVV). Search strategies, dates, and 
results for each database were recorded in an Excel workbook and are found in ESM Appendix Table 1. The last database search was conducted on May 10, 2019.

We further manually reviewed bibliographies of articles selected for analysis and conducted a cited reference search using Scopus. Cited reference searches have been found to be a more sensitive search strategy than keyword searches for identifying articles using specific measurement instruments. ${ }^{27}$ Titles and abstracts of identified citations were initially reviewed by the first author (KSH) and selected citations underwent study selection procedures. EndNote was used to store all citations found in the search process and to check for duplicates. The last cited reference search was conducted on December 17, 2019.

\section{Study Selection}

Citations and abstracts were uploaded into DistillerSR (Evidence Partners, Ottawa, Canada) for study selection. Two reviewers at any one time (KSH, JC, AG, RK) independently screened all titles and abstracts. The two reviewers met to discuss and reach consensus on differences, consulting a third reviewer (EAM) as needed. Following, two reviewers (KSH, JC) conducted independent full-text screening of included articles. Differences were discussed and consensus reached, consulting a third reviewer (EAM) as needed. Screening results using a sample of references from a preliminary search yielded a weighted average kappa value of 0.73 , indicating moderate interrater reliability. ${ }^{28}$

\section{Data Extraction}

A graphic representation of the methods used to perform data extraction, risk of bias, and summary of findings is shown in Figure 1. Two reviewers $(\mathrm{KSH}, \mathrm{JC})$ independently extracted data for each study using DistillerSR with differences resolved through discussion and consultation with a third reviewer (EAM) as needed. Study-relevant characteristics extracted included sample size, sample demographics, and setting. Measurerelevant characteristics included measure name, source reference, method of administration, composition (e.g., domains, subdomains, number of items), response options, and method of scoring. Study authors were contacted via email to identify missing information.

\section{Evaluation of Methodological Quality of Measurement Properties for Individual Studies}

After data extraction, two independent raters trained in psychometrics (KSH, JC) used the COSMIN Risk of Bias checklist to evaluate methodological quality of measurement properties in each study. ${ }^{24}$ The COSMIN Risk of Bias checklist was originally designed for patient-reported outcome measures (PROMs); minor modifications were made for our target population of professionals (ESM Appendix Table 2). The quality of each measurement property (i.e., structural validity, internal consistency, cross-cultural validity/measurement invariance, reliability, measurement error, criterion validity, hypothesis testing for construct validity, responsiveness) was rated as very good, adequate, doubtful, inadequate, or N/A. Ratings followed the "worst score counts" principle - the lowest rating of any standard for that property was taken as its overall rating. Differences were resolved through discussion and consultation with an expert psychometrician (GES).

\section{Rating Results of Measurement Properties of Individual Studies}

Following the rating of methodological quality of measurement properties of each study, two authors (KSH, JC) rated results of measurement properties in each study using Prinsen and Terwee's criteria for good measurement properties. ${ }^{24}$ Results were rated as sufficient (+), insufficient (-), or indeterminate (?) (i.e., not enough information available).

The Prinsen and Terwee protocol was further modified to omit ratings of content validity, which is more time- and resource-intensive than that of other measurement properties. It requires strong knowledge of PROM development and qualitative methodology, expertise in the field of interest (organizational culture and climate), and experience with the target population of interest for reviewers to rate the content of measures directly. Rating content validity to this standard was deemed beyond the scope of the study.

\section{Data Synthesis}

Following their appraisal, studies were grouped by measure, with results pooled into a qualitative summary for each measure. This summary was again rated against Prinsen and Terwee's quality criteria for good measurement properties to obtain a measure rating. Ratings were given as sufficient $(+)$, insufficient $(-)$, inconsistent $( \pm$ ) (i.e., no explanation found for inconsistent results), or indeterminate (?). Finally, to determine the quality of the pooled result rating, the evidence was graded using a modified Grading of Recommendations Assessment, Development, and Evaluation (GRADE) approach as high, moderate, low, or very low quality. Definitions of quality levels are in ESM Appendix Table 3. The modified GRADE approach is adapted from the standard GRADE approach; ${ }^{29}$ quality of evidence is initially assumed to be high, then downgraded based on four factors: (1) risk of bias of individual studies (i.e., COSMIN ratings of methodological quality), (2) inconsistency, (3) imprecision, and (4) indirectness. ${ }^{24}$ Rating and grading were done independently by two authors (KSH, JC). Differences were resolved through discussion and consultation with a psychometrics expert (GES) as needed.

\section{RESULTS}

\section{Study Selection}

The electronic database search yielded 1782 records, 42 of which were selected for analysis. The selection process is detailed in Figure 2. 


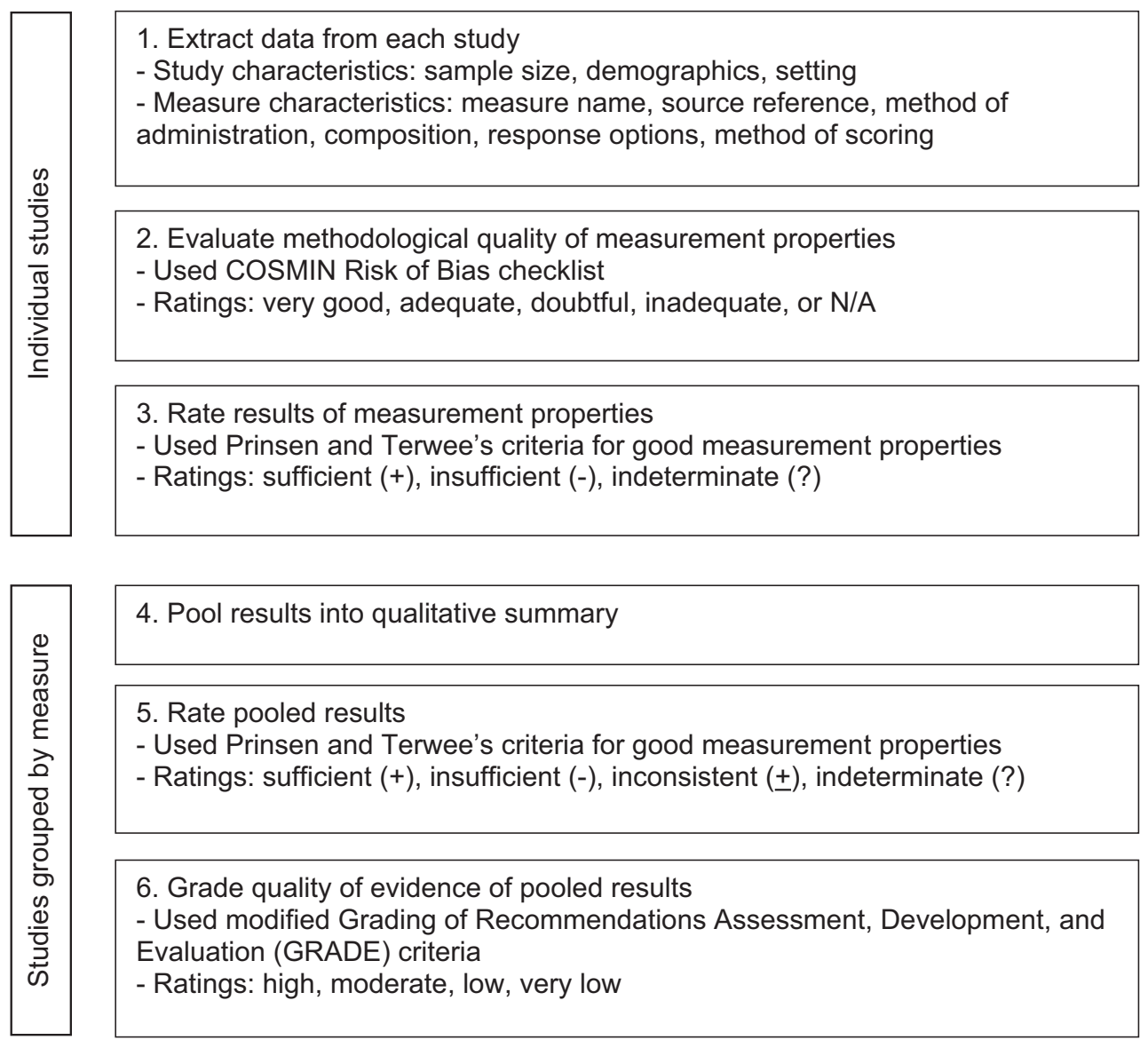

Figure 1 Data extraction, risk of bias, and summary of findings methods.

Across the 42 included studies, we identified 16 culture measures in 25 studies and 11 climate measures in 17 studies. After combining those that were variations of the same source measures (e.g., slight variations in wording or number of items; different domains or subscales), there were a total of 7 culture measures and 8 climate measures. Table 2 summarizes the measure characteristics. Measures varied in length from 15 to 50 items for organizational culture and 6 to 64 items for organizational climate. Number of domains ranged from 3 to 10 domains for culture and from 2 to 7 domains for climate. All but one measure were developed in English (Organizational Climate for Health Care Organizations, ${ }^{71}$ developed in Spanish). Most used Likert scales; however, some measures from the Competing Values Framework ${ }^{30}$ used an ipsative scale, where points are distributed among response options. Measure characteristics for individual studies can be found in ESM Appendix Table 4.

\section{Summary of Evidence}

Table 3 shows the pooled qualitative summaries of measurement properties, their ratings, and an assigned GRADE for each measure. For ratings of methodological quality and results of measurement properties of individual studies, see ESM Appendix Table 5. Breakdown of GRADE assignments can be found in ESM Appendix Table 6. Overall, the most frequently reported measurement property was internal consistency, followed by structural validity. Crosscultural validity was evaluated for two measures: the Medical Group Practice Culture Assessment (MGPCA) ${ }^{43}$ was translated into and adapted for the Italian language, ${ }^{48}$ and the revised Organizational Culture Profile ${ }^{52}$ was adapted for the Greek-Cypriot dialect. ${ }^{53}$ No psychometric properties were reported for seven culture measures and one climate measure. We describe measures that were cited by three or more studies, reported results for three or more measurement properties, have more than one measurement property with high-quality evidence, or were found to be originally developed for prim ary care (discovered through author correspondence or mentioned in the study).

Organizational Culture Measures. We summarize the findings for 3 of the 16 identified culture measures: Culture Questionnaire adapted for health care settings, Practice Culture Assessment, and revised Organizational Culture Profile. The most frequently used measure, the Culture Questionnaire adapted for health care settings, ${ }^{36}$ had insufficient internal consistency based on high-quality evidence. The Practice Culture Assessment, used by three studies, had insufficient 

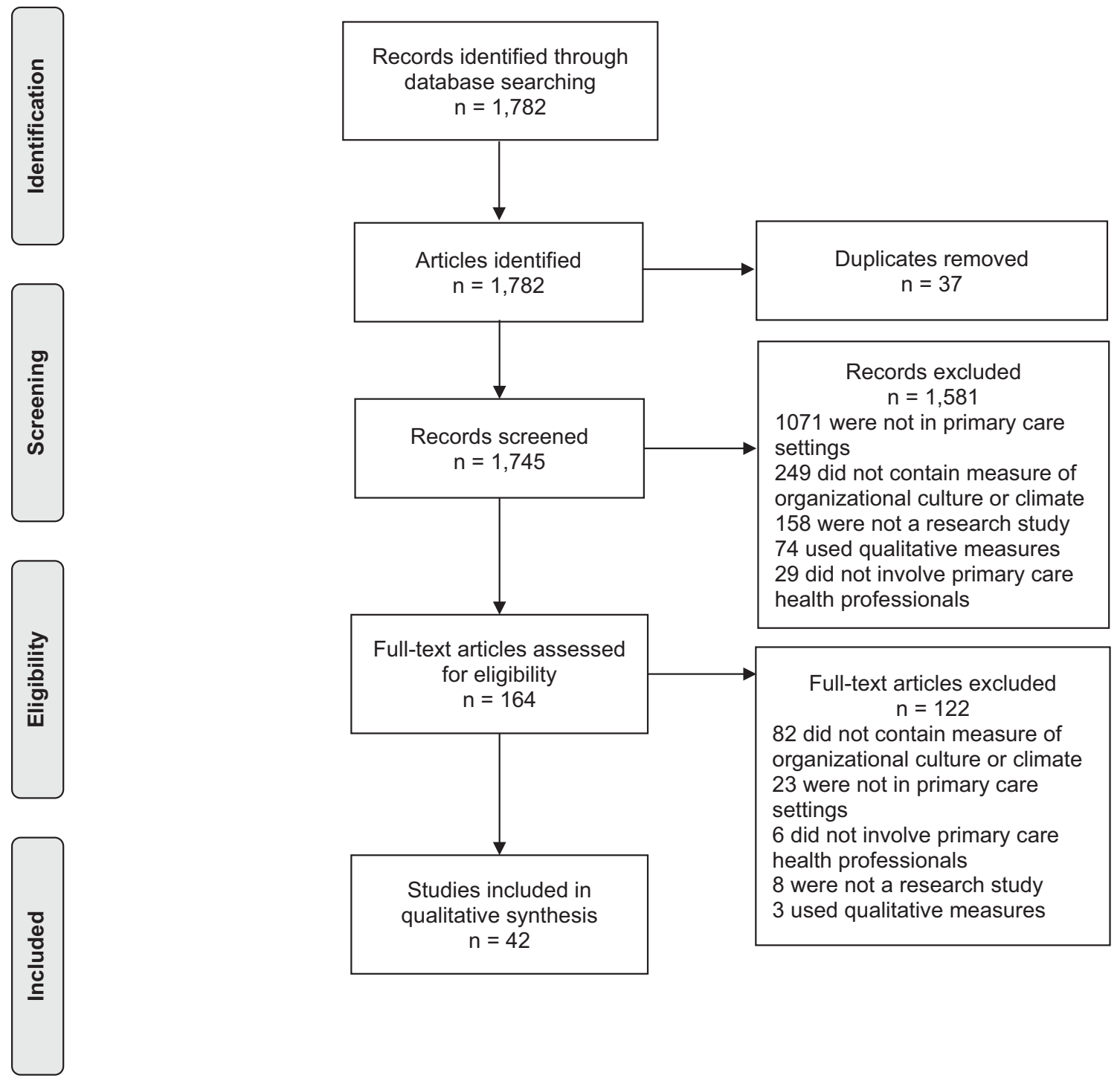

Figure 2 Preferred Reporting Items for Systematic Reviews and Meta-Analyses (PRISMA) flow diagram of the search and screening process.

structural validity based on low-quality evidence and sufficient internal consistency based on moderate-quality evidence. Reasons for low/moderate-quality evidence were indirectness of evidence due to the population being a mix of clinicians and staff and the risk of bias from a lack of very good-quality studies. The revised Organizational Culture Profile ${ }^{53}$ reported many measurement properties, albeit the majority having very low-quality of evidence due to lack of available studies of very good quality. Downgrading also occurred due to risk of bias - structural validity was performed with a small sample size, and cross-cultural validity testing lacked direct comparisons between two culturally different groups. Among all culture measures, the Practice Culture Assessment ${ }^{56}$ is the only measure that was found to be originally developed in primary care health professionals and used in its original form. The MGPCA and the Primary Care Organizational Questionnaire ${ }^{59}$ were also developed in primary care; however, the included studies use modified forms from the original measure.
Organizational Climate Measures. We summarize findings for 4 of the 11 identified climate measures: Nurse Practitioner Primary Care Organizational Culture Questionnaire (NPPCOCQ), Task and Relational Climate Scale, Practice Climate Survey, and Workplace Climate Survey. The climate measure used by most studies, all of which were by the measure developer, was the field-tested version of the NPPCOCQ. ${ }^{63}$ It also had the most reported measurement properties, with high-quality evidence for sufficient structural validity and internal consistency. The Task and Relational Climate Scale, ${ }^{7}$ derived from a larger survey administered by the Veterans Affairs, also had high-quality evidence for sufficient structural validity and internal consistency, although based on a single study. The NP-PCOCQ,${ }^{63}$ Workplace Climate Survey, ${ }^{77}$ and Practice Climate Survey ${ }^{74}$ were found to be developed in primary care settings-NP-PCOCQ with NPs and Practice Climate Survey and Workplace Climate Survey with primary care providers and staff. The Practice Climate Survey had high-quality evidence for sufficient internal consistency, 


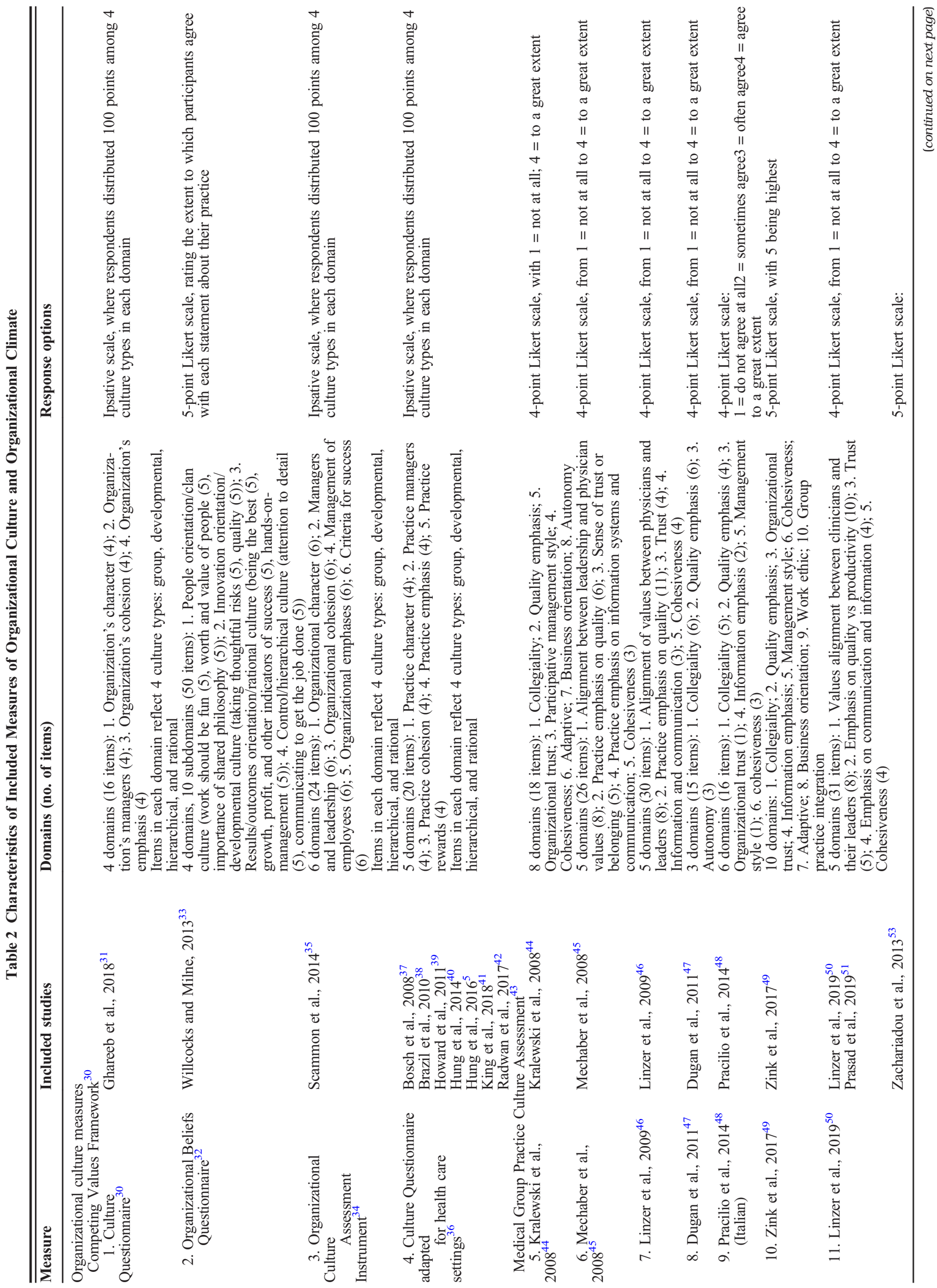




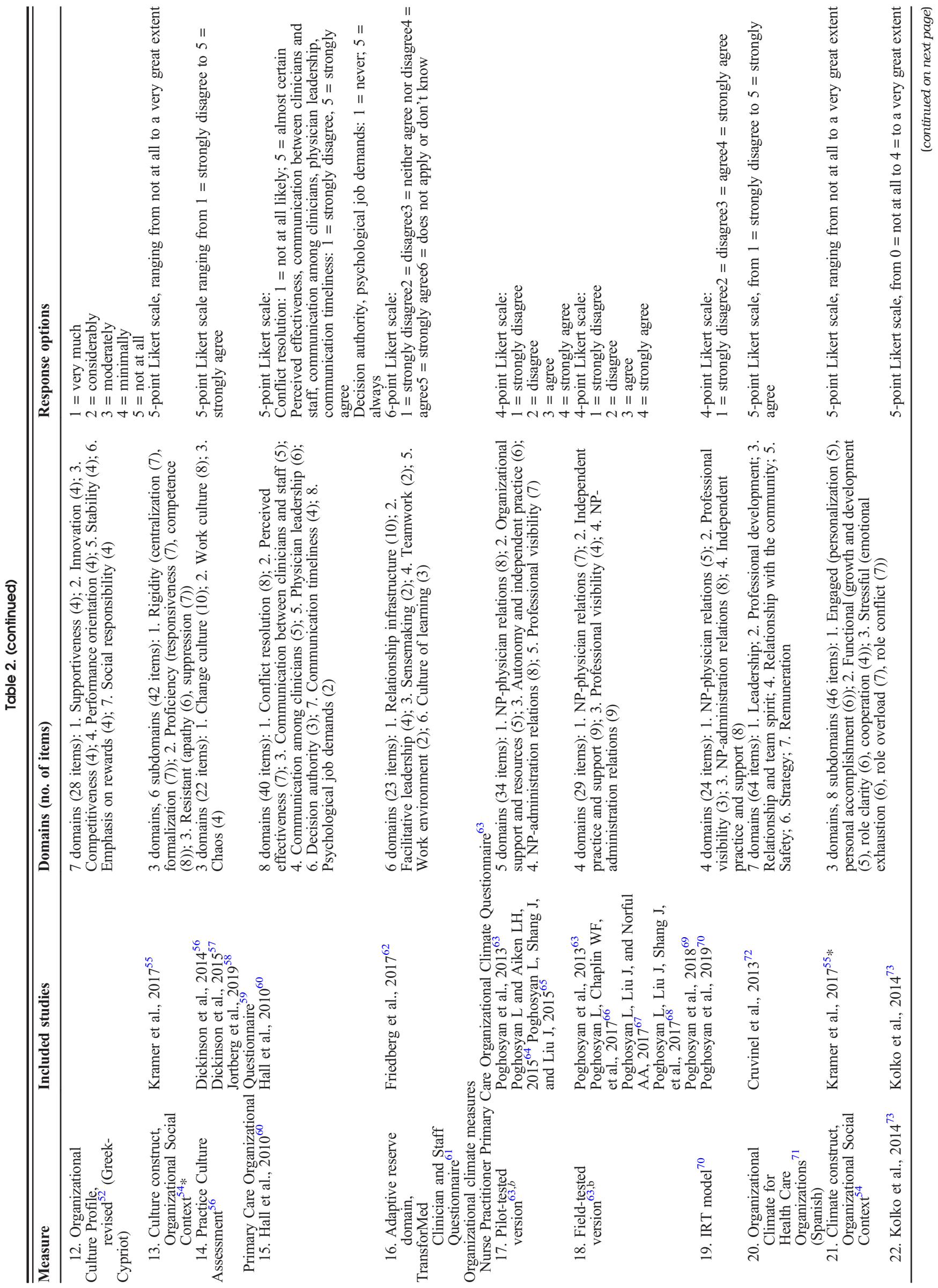


while the Workplace Climate Survey had no measurement properties of high-quality evidence.

\section{DISCUSSION}

In this systematic review, we identified and evaluated the psychometric properties of instruments used from 2008 to 2019 to measure organizational culture and organizational climate for primary health care professionals in primary care settings. Overall, we found considerable variability in measures, both conceptually, in that they differ in the domains and subdomains assessed and in psychometric quality. Only a handful of measures (6 of 27) were used in more than one study, and many studies reported limited or no psychometric information. Accordingly, we were unable to pool many psychometric results.

One explanation for the variability of measures is the lack of a consensus on what domains define these two constructs. ${ }^{9,20,80}$ Generally, the domains of management, relationship infrastructure, and trust seemed to appear in several culture measures, and leadership, teamwork, and autonomy in climate measures. Thus, while evaluating content validity against a "gold standard" remained outside of our review scope, this work serves as a reference point to better understand the breadth of available domain conceptualizations. Until such standards are developed, we suggest that when choosing an organizational culture or climate measure, in addition to considering the quality of evidence, one should consider if its domains are suitable for one's study purpose.

Lacking robust high-quality evidence, we cannot confidently recommend any one measure for use in measuring organizational culture or climate in primary care. We highlight below some of the most promising measures based on the evidence available so far. In choosing these measures, we consider its frequency of use, evidence for robust measurement properties, and if it was originally developed in primary care.

\section{Recommendations: Organizational Culture}

The Culture Questionnaire adapted for health care settings ${ }^{36}$ is the most frequently used measure of organizational culture in this review. It uses an ipsative scale design, where the respondent distributes 100 points among four items, each representing a culture type. With ipsative scales, the items are interdependent, which may confound validity and reliability (e.g., internal consistency, factor analysis). However, this design allows culture to be interpreted as a composition of multiple cultures to varying degrees, which may better represent true culture. Additionally, its widespread use makes it easily comparable across studies.

The Practice Culture Assessment ${ }^{56}$ is a newer scale originally developed in primary care settings. Testing the measurement properties of this measure for clinicians separately from staff who do not provide patient care can increase the quality of evidence for its psychometric properties. 


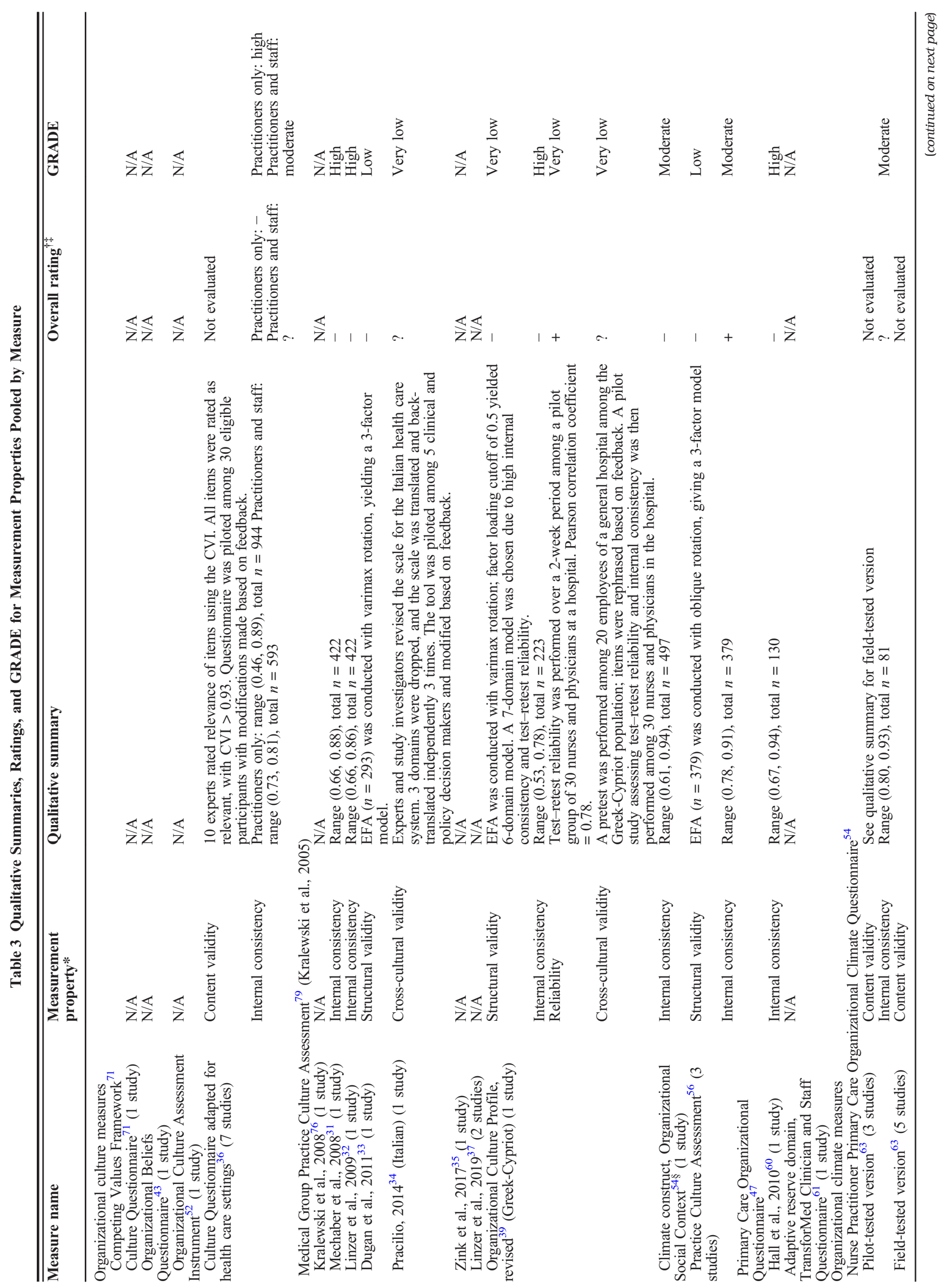




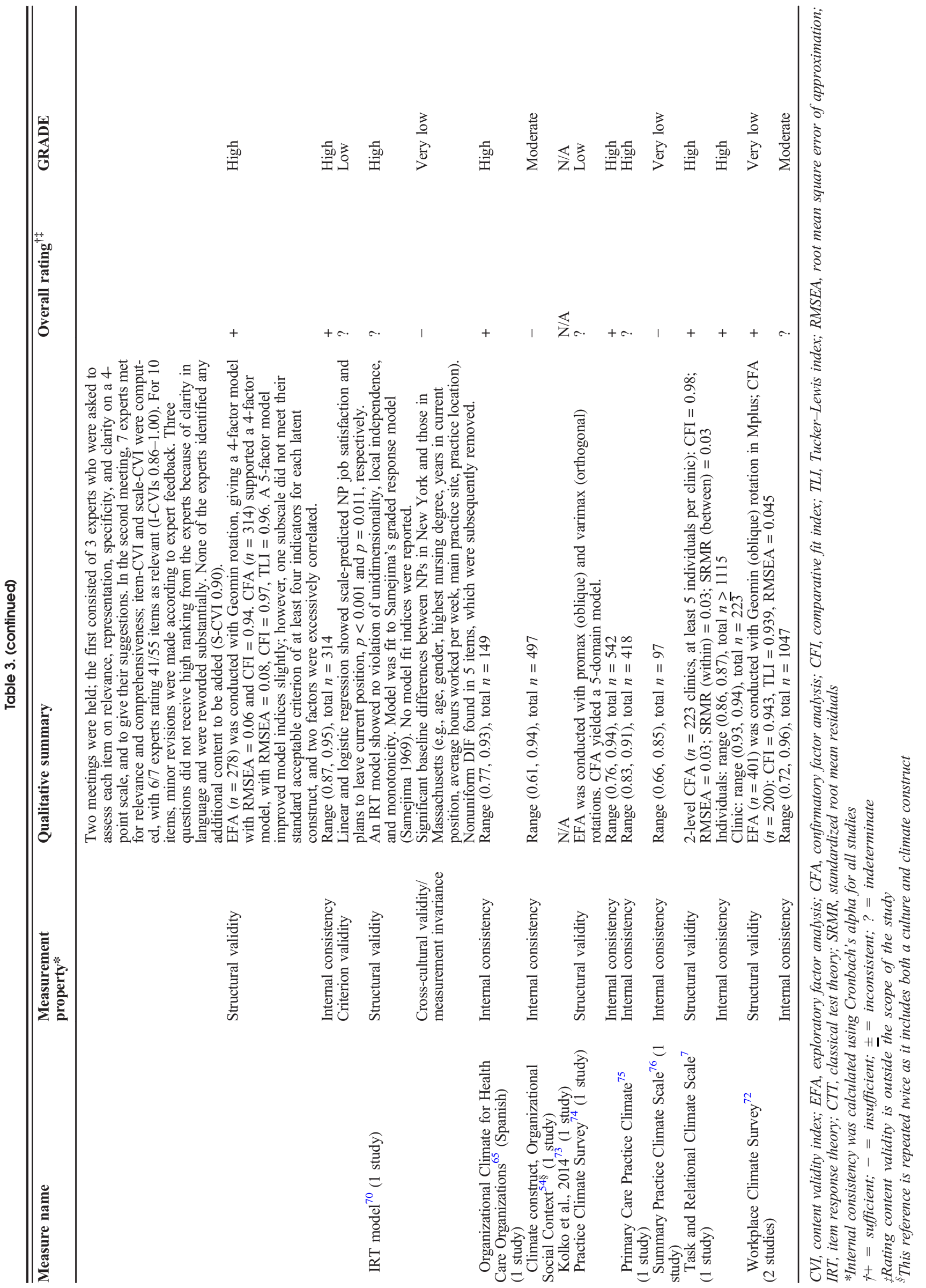


The MGPCA ${ }^{43}$ is worth considering as it is a frequently cited source measure by several of our included studies and was also developed for primary care. ${ }^{43}$ Because each of the included studies used modified versions of the MGPCA that all lack strong validity evidence, clear recommendations cannot be made about which specific version to use. The developers recommend their most up-to-date version, a 17-item measure with eight domains (not included in this review). Testing psychometric properties of this scale and its modified versions is warranted for future use.

\section{Recommendations: Organizational Climate}

Among organizational climate measures, the field-tested version of the NP-PCOCQ ${ }^{63}$ for nurse practitioners has the strongest psychometric evidence, with high-quality evidence for sufficient structural validity and internal consistency. Further strengthening of this tool necessitates validation by investigators independent of the scale developers.

The Practice Climate Survey ${ }^{74}$ and the Task and Relational Climate Scale ${ }^{7}$ are more recently developed measures that have been developed in primary care. Additionally, they have at least one good measurement property based on strong evidence, although this is based on a single study for each. These measures would benefit from additional use and validation.

We caution users who may be applying these measures to their own work that, when aggregating individual results to the organizational level using means (as many of our included studies had done), variability is overlooked, resulting in information loss and bias. ${ }^{79}$ Thus, aggregated results should be interpreted accordingly.

\section{Limitations}

While COSMIN guidelines provide a strong framework for systematic evaluation of measures, there were two areas where adaptations to these guidelines were necessary in the current review. First, as COSMIN guidelines are tailored to patientreported outcome measure evaluation, we adapted the scope for relevance to a target population of health care professionals (ESM Appendix Table 2). Second, evaluation of content validity was omitted, as there was insufficient consensus in the literature to provide a gold standard for evaluating conceptual domain scope. Consequently, the ratings assigned in this review should be considered conservative.

At a review level, we recognize that all studies may not have published all methods and results of the measurement properties for the measures they used. This could negatively impact the ratings of methodological quality that were assigned to them and, subsequently, our final recommendations. To mitigate this limitation, we attempted to contact authors by email to fill in missing information when possible.

\section{Future Directions}

Based on our review of organizational culture and climate measures, we offer suggestions to build upon this work. Foremost, investigators should consider drawing on or expanding upon existing tools, before developing new competing tools in this milieu. Further validation is particularly warranted when adapting existing tools to other diverse settings or populations within primary care, expanding into new subdomains, creating short forms from already validated measures, or recalibrating scoring procedures.

Additionally, clinicians should be examined separately from nonclinical staff when measuring organizational culture or climate. For the Culture Questionnaire adapted for health care settings, pooled internal consistency results improved markedly when practitioners only were examined, compared to when practitioners and staff were examined together (Table 3). The study of Becker et al. ${ }^{76}$ illustrates how clinicians and staff were given separate, structurally different versions of a climate instrument.

The field of organizational culture and climate is one that is constantly conceptually expanding, ${ }^{10}$ with no consensus by which these constructs should be measured. ${ }^{20}$ The dynamic nature of this field presents as a limitation to its objective measurement, as demonstrated in our review. The question remains on what the best way is to objectively measure organizational culture and climate. It may require a completely new measure with a more inclusive conceptual framework, or multiple measures to capture the diversity of the concept. To work toward filling these research gaps, one research team has proposed key dimensions to comprise organizational culture in primary care. ${ }^{6}$ Future work may build upon or confirm similar work and move toward designing standards for these constructs in primary care.

\section{Conclusion}

In conclusion, we present a systematic review on instruments that measure organizational culture and climate in primary care settings. A variety of measures were found with diverse and nonuniform dimensions. Overall, more high-quality evidence on their measurement properties in primary care is needed. The lack of a standard framework for culture and climate could be contributing to the difficulty in performing rigorous validity testing. Suggestions for further research include better measurement and reporting of the psychometric properties of existing instruments, exploring differences in culture and climate between practitioners and support staff, and supporting work toward standardizing dimensions for these constructs. We hope that compiling organizational culture and climate measures in a single review can help researchers make more informed decisions when choosing a measure or when deciding to develop a new one.

Acknowledgments: The authors would like to acknowledge Ashlynd Gogas, BS, and Rachel Kaffey, BS, for their diligent, efficient, and excellent contribution to the screening of titles and abstracts of records from our search. 
Corresponding Author: Kimberly S. Hsiung, MD, MS; Clinical and Translational Science Institute, University of Pittsburgh, Pittsburgh, PA, USA (e-mail: ksl49@pitt.edu).

Funding This study was funded by the Clinical Scientist Training Program, sponsored by the Clinical and Translational Sciences Institute at the University of Pittsburgh School of Medicine, Pittsburgh, PA, and the Roth Fellow Award for medical student research projects in psychiatry, behavioral medicine, and basic and applied research of the brain and its functioning.

\section{Compliance with Ethical Standards:}

Conflict of Interest: The authors have no other conflicts of interest to disclose.

\section{REFERENCES}

1. Bates DW. Primary care and the US health care system: what needs to change? J Gen Intern Med 2010:25(10):998-999.

2. Kim LY, Rose DE, Soban LM, Stockdale SE, Meredith LS, Edwards ST, et al. Primary care tasks associated with provider burnout: findings from a veterans health administration survey. $J$ Gen Intern Med 2017;33(1):50-56.

3. Gardner RL, Cooper E, Haskell J, Harris DA, Poplau S, Kroth PJ, et al. Physician stress and burnout: the impact of health information technology. J Am Med Inform Assoc 2018;26(2):106-114.

4. Dall TM, Gallo PD, Chakrabarti R, West T, Semilla AP, Storm MV. An aging population and growing disease burden will require a large and specialized health care workforce by 2025. Health Aff 2013;32(11):20132020.

5. Hung D, Chung S, Martinez M, Tai-Seale M. Effect of organizational culture on patient access, care continuity, and experience of primary care. J Ambul Care Manag 2016;39(3):242-252.

6. Grant S, Guthrie B, Entwistle V, Williams B. A meta-ethnography of organisational culture in primary care medical practice. $J$ Health Organ Manag 2014;28(1):21-40.

7. Benzer JK, Young G, Stolzmann K, Osatuke K, Meterko M, Caso A, et al. The relationship between organizational climate and quality of chronic disease management. Health Serv Res 2011;46(3):691-711.

8. Cooke RA, Rousseau DM. Behavioral norms and expectations: a quantitative approach to the assessment of organizational culture. Group Organ Stud 1988;13(3):245

9. Gershon RR, Stone PW, Bakken S, Larson E. Measurement of organizational culture and climate in healthcare. J Nurs Adm 2004;34(1):33-40

10. Verbeke W. Exploring the conceptual expansion within the field of organizational behaviour: organizational climate and organizational culture. J Manag Stud 1998;35(3):303-329.

11. Schneider B, Brief AP, Guzzo RA. Creating a climate and culture for sustainable organizational change. Organ Dyn 1996;24(4):7-19.

12. Glisson C, James LR. The cross-level effects of culture and climate in human service teams. J Organ Behav 2002;23(6):767-794.

13. Rabatin J, Williams E, Manwell LB, Schwartz MD, Brown RL, Linzer M. Predictors and outcomes of burnout in primary care physicians. J Prim Care Community Health 2016;7(1):41-43.

14. Nembhard IM, Alexander JA, Hoff TJ, Ramanujam R. Why does the quality of health care continue to lag? Insights from management research. Acad Manag Perspect 2009;23(1):24-42.

15. Williams B, Perillo S, Brown T. What are the factors of organisational culture in health care settings that act as barriers to the implementation of evidence-based practice? A scoping review. Nurse Educ Today 2015;35(2):e34-41.

16. Tabriz AA, Birken SA, Shea CM, Fried BJ, Viccellio P. What is full capacity protocol, and how is it implemented successfully? Implement Sci 2019; 14(73): 1-13.

17. Olson K, Marchalik D, Farley H, Dean SM, Lawrence EC, Hamidi MS, et al. Organizational strategies to reduce physician burnout and improve professional fulfillment. Curr Probl Pediatr Adolesc Health Care 2019;49.

18. Smith CD, Balatbat C, Corbridge S, Dopp AL, Fried J, Harter R, et al. Implementing optimal team-based care to reduce clinician burnout. NAM
Perspectives [discussion paper]. 2018; https://nam.edu/implementingoptimal-team-based-care-to-reduce-clinician-burnout. Accessed 25 February 2020.

19. Bronkhorst BAC, Tummers LG, Steijn AJ, Vijverberg D. Organizational climate and employee mental health outcomes - a systematic review of studies in health care organizations. Health Care Manag Rev 2015;40(3):254-271.

20. Scott T, Mannion R, Davies H, Marshall M. The quantitative measurement of organizational culture in health care: a review of the available instruments. Health Serv Res 2003;38(3):923-945.

21. Tallia AF, Stange KC, Reuben R. McDaniel J, Aita VA, Miller WL, Crabtree BF. Understanding organizational designs of primary care practices. J Healthc Manag 2003;48(1):45.

22. Moher D, Liberati A, Tetzlaff J, Altman D, Group TP. Preferred reporting items for systematic reviews and meta-analyses: the PRISMA statement. J Clin Epidemiol 2009.

23. Mokkink LB, Vet HCWD, Prinsen CAC, Patrick DL, Alonso J, Bouter LM, et al. COSMIN risk of bias checklist for systematic reviews of patientreported outcome measures. Qual Life Res 2018;27:1171-1179.

24. Prinsen CAC, Mokkink LB, Bouter LM, Alonso J, Patrick DL, Vet HCWd, et al. COSMIN guideline for systematic reviews of patientreported outcome measures. Qual Life Res 2018;27:1147-1157.

25. Terwee CB, Prinsen CAC, Chariatto A, Westerman MJ, Patrick DL, Alonso J, et al. COSMIN methodology for evaluating the content validity of patient-reported outcome measures: a Delphi study. Qual Life Res 2018;27:1159-1170.

26. Jackson JL, Kuriyama A, Anton A, Choi A, Fournier JP, Geier AK, et al. The accuracy of Google Translate for abstracting data from nonEnglish-language trials for systematic reviews. Ann Intern Med 2019;171(9):677-679.

27. Linder SK, Kamath GR, Pratt GF, Saraykar SS, Volk RJ. Citation searches are more sensitive than keyword searches to identify studies using specific measurement instruments. J Clin Epidemiol 2015;68:412417.

28. McHugh ML. Interrater reliability: the kappa statistic. Biochem Med (Zagreb) 2012;22(3):276-282.

29. GRADE. Handbook for grading the quality of evidence and the strength of recommendations using the GRADE approach. In: Schunemann $\mathrm{H}$, Brozek J, Guyatt G, Oxman A, eds. GRADE Handbook. 2013: https:// gdt.gradepro.org/app/handbook/handbook.html. Accessed 15 May, 2020.

30. Guinn RE, Kimberly JR. Paradox, planning, and perseverance: guidelines for managerial practice. In: Kimberly JR, Quinn RE, eds. Managing Organization Transitions. Homewood: Dow Jones-Irwin; 1984:295-313.

31. Ghareeb A, Said H, El Zoghbi M. Examining the impact of accreditation on a primary healthcare organization in Gatar. BMC Med Educ 2018;18(1):216.

32. Sashkin M. Pillars of Excellence: Organisational Beliefs Questionnaire. Bryn Mawr: Carmarthen; 1984.

33. Willcocks SG, Milne P. The Medical Leadership Competency Framework: challenges raised for GP educators by a pilot study of culture in general practice. Educ Prim Care 2013;24(1):29-33.

34. Cameron K, Quinn R. Diagnosing and Changing Organizational Culture: Based on the Competing Values Framework. Reading: Addison-Wesley; 1999.

35. Scammon DL, Tabler J, Brunisholz K, Gren LH, Kim J, TomoaiaCotisel A, et al. Organizational culture associated with provider satisfaction. J Am Board Fam Med 2014;27(2):219-228.

36. Shortell SM, Jones RH, Rademaker AW, Gillies RR, Dranove DS, Hughes EFX, et al. Assessing the impact of total quality management and organizational culture on multiple outcomes of care for coronary artery bypass graft surgery patients. Med Care 2000;38(2):207-217.

37. Bosch $\mathbf{M}$, Dijkstra $\mathbf{R}$, Wensing $\mathbf{M}$, van der Weijden $\mathbf{T}$, Grol $\mathbf{R}$. Organizational culture, team climate and diabetes care in small officebased practices. BMC Health Serv Res 2008;8:180.

38. Brazil K, Wakefield DB, Cloutier MM, Tennen H, Hall CB. Organizational culture predicts job satisfaction and perceived clinical effectiveness in pediatric primary care practices. Health Care Manag Rev 2010;35(4):365-371.

39. Howard M, Brazil K, Akhtar-Danesh N, Agarwal G. Self-reported teamwork in family health team practices in Ontario: organizational and cultural predictors of team climate. Can Fam Physician 2011;57(5):e185191.

40. Hung DY, Leidig R, Shelley DR. What's in a setting?: influence of organizational culture on provider adherence to clinical guidelines for treating tobacco use. Health Care Manag Rev 2014;39(2):154-163. 
41. King MA, Wissow LS, Baum RA. The role of organizational context in the implementation of a statewide initiative to integrate mental health services into pediatric primary care. Health Care Manag Rev 2018;43(3):206-217.

42. Radwan M, Akbari Sari A, Rashidian A, Takian A, Abou-Dagga S, Elsous A. Influence of organizational culture on provider adherence to the diabetic clinical practice guideline: using the competing values framework in Palestinian Primary Healthcare Centers. Int J Gen Med 2017; 10:239-247.

43. Kralewski J, Dowd BE, Kaissi A, Curoe A, Rockwood T. Measuring the culture of medical group practices. Health Care Manag Rev 2005;30(3):184-193.

44. Kralewski JE, Dowd BE, Cole-Adeniyi T, Gans D, Malakar L, Elson B. Factors influencing physician use of clinical electronic information technologies after adoption by their medical group practices. Health Care Manag Rev 2008;33(4):361-367.

45. Mechaber HF, Levine RB, Manwell LB, Mundt MP, Linzer M, Schwartz M, et al. Part-time physicians...prevalent, connected, and satisfied. J Gen Intern Med 2008;23(3):300-303.

46. Linzer M, Manwell LB, Williams ES, Bobula JA, Brown RL, Varkey AB, et al. Working conditions in primary care: physician reactions and care quality. Ann Intern Med. 2009;151(1):28-36, w26-29.

47. Dugan, D P, Mick, S S, Scholle, $\mathbf{S} \mathbf{H}$, et al. The relationship between organizational culture and practice systems in primary care. J Ambul Care Manag 2011;34(1):47-56.

48. Pracilio VP, Keith SW, McAna J, Rossi G, Brianti E, Fabi M, et al. Primary care units in Emilia-Romagna, Italy: an assessment of organizational culture. Am J Med Qual 2014;29(5):430-436.

49. Zink T, Kralewski J, Dowd B. The transition of primary care group practices to next generation models: satisfaction of staff, clinicians, and patients. J Am Board Fam Med 2017;30(1):16-24

50. Linzer M, Poplau S, Prasad K, Khullar D, Brown R, Varkey A, et al. Characteristics of health care organizations associated with clinician trust: results from the Healthy Work Place Study. JAMA Netw Open 2019;2(6).

51. Prasad K, Poplau S, Brown R, Yale S, Grossman E, Varkey AB, et al. Time pressure during primary care office visits: a prospective evaluation of data from the Healthy Work Place Study. J Gen Intern Med 2020;35:465-472.

52. Sarros JC, Gray J, Densten IL, Cooper B. The organizational culture profile revisited and revised: an Australian perspective. Aust J Manag 2005;30(1):159-182.

53. Zachariadou T, Zannetos S, Pavlakis A. Organizational culture in the primary healthcare setting of Cyprus. BMC Health Serv Res 2013;13:112.

54. Glisson C, Landsverk J, Schoenwald S, Kelleher K, Hoagwood KE, Mayberg S, et al. Assessing the organizational social context (OSC) of mental health services: implications for research and practice. Admin Pol Ment Health 2008;35:98-113.

55. Kramer TL, Drummond KL, Curran GM, Fortney JC. Assessing culture and climate of federally qualified health centers: a plan for implementing behavioral health interventions. J Health Care Poor Underserved 2017;28(3):973-987.

56. Dickinson WP, Dickinson LM, Nutting PA, Emsermann CB, Tutt B, Crabtree BF, et al. Practice facilitation to improve diabetes care in primary care: a report from the EPIC randomized clinical trial. Ann Fam Med 2014;12(1):8-16.

57. Dickinson LM, Dickinson WP, Nutting PA, Fisher L, Harbrecht $\mathbf{M}$ Crabtree BF, et al. Practice context affects efforts to improve diabetes care for primary care patients: a pragmatic cluster randomized trial. J Gen Intern Med 2015;30(4):476-482.

58. Jortberg BT, Fernald DH, Hessler DM, Dickinson LM, Wearner R, Connelly $\mathbf{L}$, et al. Practice characteristics associated with better implementation of patient self-management support. J Am Board Fam Med 2019;32(3):329-340.

59. Hall CB, Tennen H, Wakefield DB, Brazil K, Cloutier MM. Organizational assessment in paediatric primary care: development and initial validation of the primary care organizational questionnaire. Health Serv Manag Res 2006;19:207-214.

60. Hall, C B, Brazil, K, Wakefield, D, et al. Organizational culture, job satisfaction, and clinician turnover in primary care. J Prim Care Community Health 2010;1(1):29-36.

61. Jaen CR, Crabtree BF, Palmer RF, Ferrer RL, Nutting PA, Miller WL, et al. Methods for evaluating practice change toward a patient-centered medical home. Ann Fam Med 2010;8:s9-s20.

62. Friedberg MW, Reid RO, Timbie JW, Setodji C, Kofner A, Weidmer B, et al. Federally qualified health center clinicians and staff increasingly dissatisfied with workplace conditions. Health Aff (Millwood) 2017;36(8): 1469-1475.

63. Poghosyan L, Nannini A, Finkelstein SR, Mason E, Shaffer JA Development and psychometric testing of the nurse practitioner primary care organizational climate questionnaire. Nurs Res 2013;62(5):325-334

64. Poghosyan L, Aiken LH. Maximizing nurse practitioners' contributions to primary care through organizational changes. J Ambul Care Manag 2015;38(2):109-117

65. Poghosyan L, Shang J, Liu J, Poghosyan H, Liu N, Berkowitz B. Nurse practitioners as primary care providers: creating favorable practice environments in New York State and Massachusetts. Health Care Manag Rev 2015;40(1):46-55.

66. Poghosyan L, Chaplin WF, Shaffer JA. Validation of Nurse Practitioner Primary Care Organizational Climate Questionnaire: a new tool to study nurse practitioner practice settings. J Nurs Meas 2017;25(1): 142-155.

67. Poghosyan L, Liu J, Norful AA. Nurse practitioners as primary care providers with their own patient panels and organizational structures: a cross-sectional study. Int J Nurs Stud 2017;74:1-7.

68. Poghosyan L, Liu J, Shang J, D'Aunno T. Practice environments and job satisfaction and turnover intentions of nurse practitioners: implications for primary care workforce capacity. Health Care Manag Rev 2017;42(2):162-171.

69. Poghosyan L, Norful AA, Liu J, Friedberg MW. Nurse Practitioner practice environments in primary care and quality of care for chronic diseases. Med Care 2018;56(9):791-797.

70. Poghosyan L, Ghaffari A, Shaffer J. Nurse practitioner primary care organizational climate questionnaire: item response theory and differential item functioning. J Clin Nurs 2019;28(15-16):2934-2945.

71. Menezes IG, Sampaio LR, Gomes ACP, Teixeira FS, Santos PdS [Organizational climate scale for health organizations: development and factorial structure]. Psicol Estud 2009;26(3):301-316.

72. Cruvinel, E, Richter, K P, Bastos, R R, et al. Screening and brief intervention for alcohol and other drug use in primary care: associations between organizational climate and practice. Addict Sci Clin Pract 2013;8:4.

73. Kolko DJ, Campo J, Kilbourne AM, Hart J, Sakolsky D, Wisniewski S. Collaborative care outcomes for pediatric behavioral health problems: a cluster randomized trial. Pediatrics. 2014;133(4):e981-992.

74. Grace SM, Rich J, Chin W, Rodriguez HP. Implementing interdisciplinary teams does not necessarily improve primary care practice climate. Am J Med Qual 2016;31(1):5-11.

75. Rodriguez, H P, Meredith, L S, Hamilton, A B, et al. Huddle up!: the adoption and use of structured team communication for VA medical home implementation. Health Care Manag Rev 2015;40(4):286-299.

76. Becker ER, Roblin DW. Translating primary care practice climate into patient activation: the role of patient trust in physician. Med Care 2008;46(8):795-805.

77. Friedberg MW, Rodriguez HP, Martsolf GR, Edelen MO, Bustamante AV, Vargas Bustamante A. Measuring workplace climate in community clinics and health centers. Med Care 2016;54(10):944-949.

78. Martsolf GR, Ashwood S, Friedberg MW, Rodriguez HP. Linking structural capabilities and workplace climate in community health centers. Inquiry. 2018;55:46958018794542.

79. Clark W, Avery $\mathbf{K L}$. The effects of data aggregation in statistical analysis. Geogr Anal 1976;8.

80. Benzer J, Horner M. A meta-analytic integration and test of psychological climate dimensionality. Hum Resour Manag 2015;54(3):457-482.

Publisher's Note: Springer Nature remains neutral with regard to jurisdictional claims in published maps and institutional affiliations. 